\title{
Measuring Productivity: Issues Arising From Outsourcing And Merger Activities
}

Mercedes Marshall, Institute of Textile Technology at NC State University, USA Helmut Hergeth, College of Textiles at NC State University, USA

\begin{abstract}
The paper discusses productivity measurement issues as companies engage in outsourcing and merger activities, and links productivity measures to competitiveness. Need for new productivity approaches is presented.
\end{abstract}

\section{INTRODUCTION}

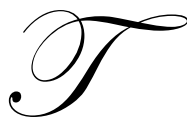

he textile and apparel industries in the United States have a long history of productivity improvements that exceed those of other regions (Baumol, 1984; Ramcharran, 2001; R. Reichard, 2000). Yet domestic companies continue to engage in outsourcing to improve their cost positions, and as trade barriers gradually decrease the foreign market share of US textile market continues to increase, especially for imports from the Asia Pacific region (Felgner, 2005; Milberg, 2004). Superior productivity is usually associated with competitiveness, and the paper evaluates if traditional manufacturing productivity measures are adequate to evaluate competitiveness.

In addition to outsourcing, the textile industry sees ongoing merger activity in a non-growth market. The paper investigates the goals and outcomes of merger activity in this industry and considers if productivity is one of the considerations. The research was sponsored by the Institute of Textile Technology (ITT) at NC State's College of Textiles.

\section{PRODUCTIVITY AND COMPETITIVENESS}

The competitiveness of an industry is often linked to its productivity, and productivity measures are used to describe, control, and improve an industry's competitive position (Drucker, 1974, Porter, 1990). While the labor productivity in the textile industry continually improved (see Figure 1) at a higher rate than in other regions and above the manufacturing average, the decline in number of plants and companies and the increase in import penetration indicate that the competitive situation of the US textile industry did not improve.

One explanation is of course the self-fulfilling premise that labor productivity must go up if measured as overall output relative to direct labor input. When a company outsources, it incurs a higher material cost (intermediate input increases in value), but it experiences lower labor cost because the labor or operator activities now happen outside of the company. As Figure 2 shows, the US textile industry outsources a significant share for most of its subsectors. This problem can be avoided by calculating labor productivity as added value relative to labor input. Comparing the two productivities should show if outsourcing does cause a significant improvement of labor productivity, but research by Marshall (Marshall, 2007) showed that the two productivity measures did not show a statistically significant difference. Consequently manufacturing productivity alone does not sufficiently describe the competitive situation of the industry; the productivity of knowledge workers (Drucker, 2000) has clearly started to play a much larger role in describing and measuring competitiveness in the textile industry. 


\section{Figure 1: Labor Productivity in the US Textile Industry (based on statistics of the US Bureau of Labor)}

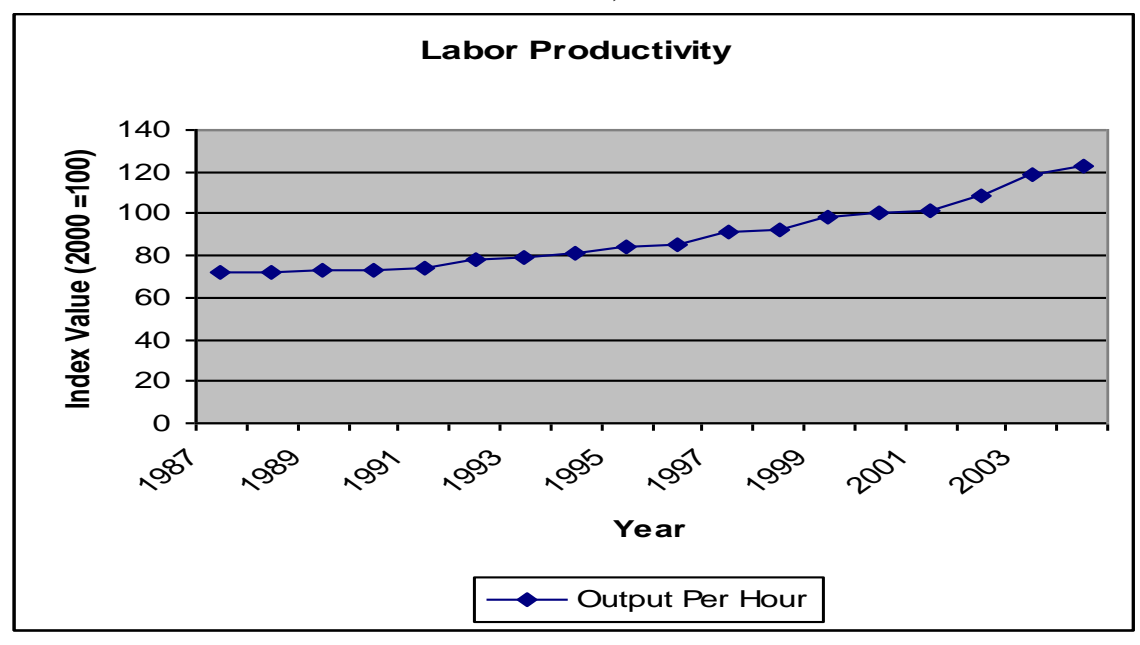

Figure 2: Outsourcing in the US Textile Industry (Marshall, 2007, also OTEXA and Bureau of Industry and Security, Department of Commerce)

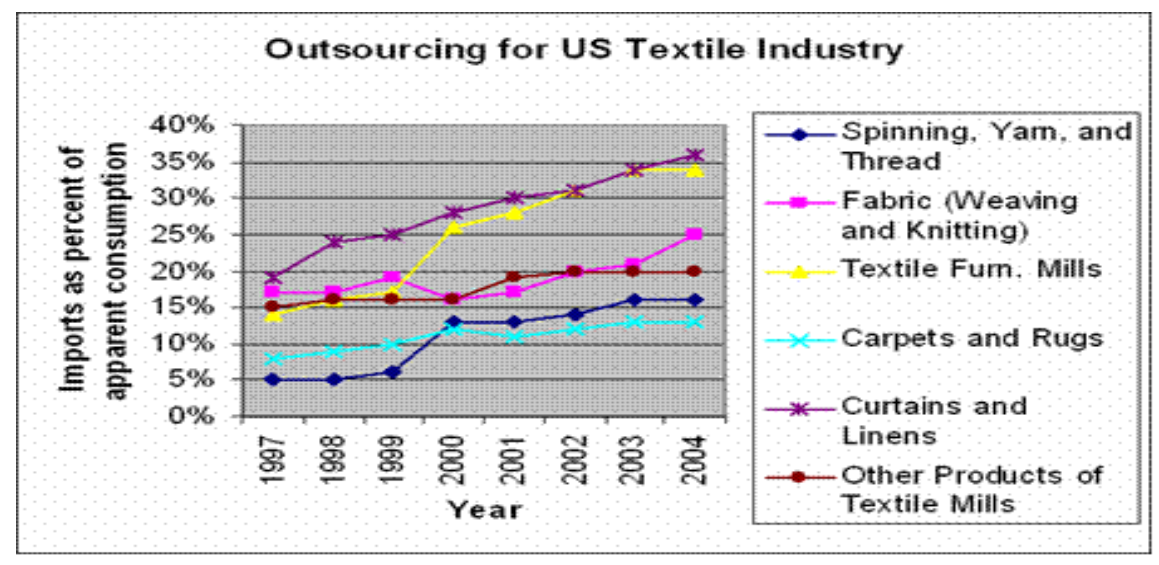

This means that outsourcing activity may improve a company's labor cost situation, but it alone does not describe the competitive situation, nor does it alone make up a sustainable competitive strategy.

\section{MERGER ACTIVITY}

The US textile industry shows continued merger activity, resulting in fewer domestic players. Mergers should lead to a bundling of resources, thus some synergies, and hopefully to productivity improvements, to economies of scale, and to less competition and therefore more profitable pricing. In practice, however, many mergers fall short of their intended goals, and the cost timeframe of integrating two companies often exceeds the planned cost and time (e.g., Sutton, 2006, The Economist, 1999). Some previous studies indicated non-quantified improvements in productivities of management teams (S.N. Kaplan, Mitchell, and Wruck, 2000). 
The US textile industry has seen ongoing merger activity, and as Figure 3 shows this activity is no longer limited to the largest companies in the industry.

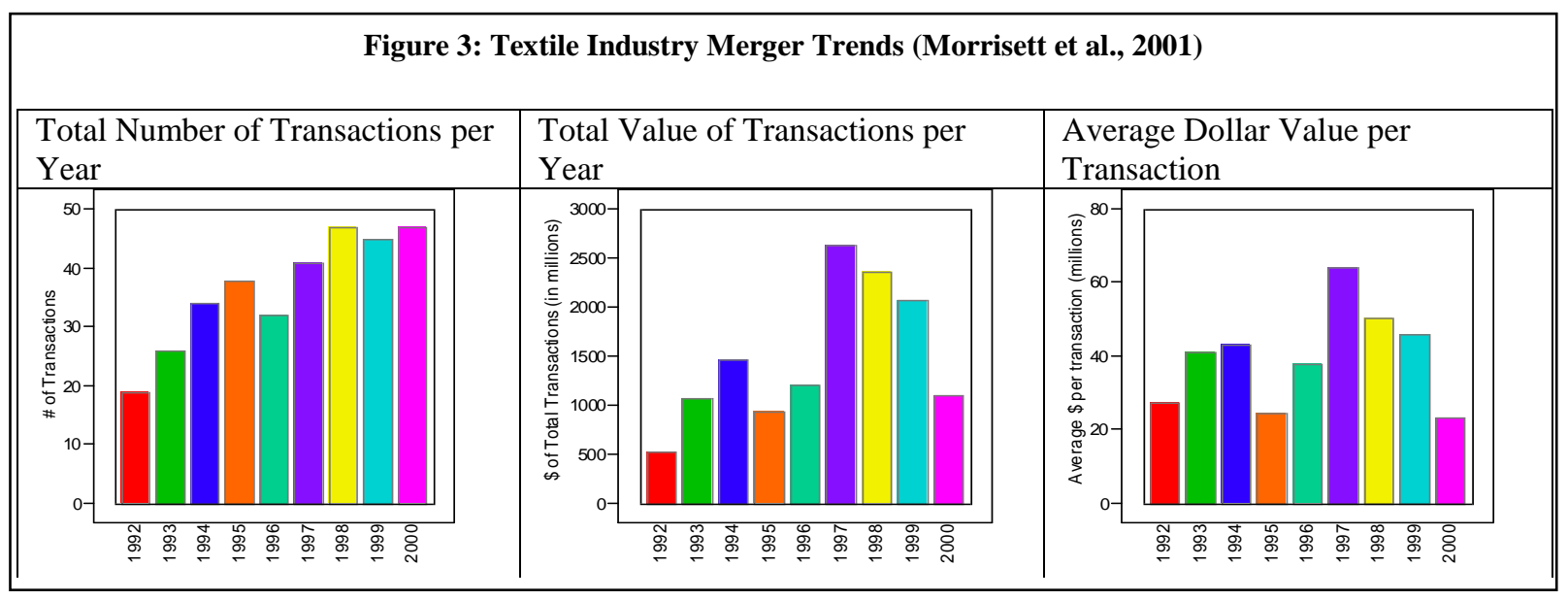

Mergers have been shown to improve stock value and thus stockholder return at least in the short run, but evidence of other measured outcomes tends to be mixed. Thus the Institute of Textile Technology at NC State's College of Textiles surveyed a number of textile companies to investigate how pre-merger goals were measured and achieved after the actual merger. While improved productivity may be an underlying goal, the expressed goals are listed in Table 1. As the US textile industry in many sectors is stagnant or in some cases even shrinking, the merger motives are mostly defensive. In growing market sectors goals were expected to be to "quickly increase market share" or "efficient access to new technologies". Key goals in the surveyed traditional textile sectors, however, were "maintaining market share" and "realizing synergies". The underlying drivers were a loss of competitiveness the companies experienced, and increasing offshore outsourcing.

Especially the stated goal of "maintaining market share" shows the defensive character of the textile merger activity which was triggered by loss of competitiveness and increasing import penetration, i.e., increased competition. Consequently the outcome of the merger is primarily measured as realized cost savings. Ultimately utilizing synergies means to eliminate duplication of resources, i.e., reducing the overall resource requirements. This leads to capacity consolidations with resulting labor force reductions, as typically the equipment with the highest productivity levels would be retained. At the corporate level, the merged companies will typically eliminate duplication of functions as well, thus reducing the total overhead cost. The resulting merged company would have similar market share than the two original companies but less capacity and therefore higher capacity utilization, a combined corporate overhead that is less costly than two separate corporate overheads. Tables 2 and 3 show the result on Human Resources as well as on Physical Resources - the merged companies try to retain the best and spin off less efficient resources.

On the other side, merging companies do not necessarily have duplication of their production capacities and product ranges. In many cases the merging companies have complimentary product ranges which allow them to provide better and more efficient marketing, as well as offering more complete solutions to their customers. In this case the merger is not purely defensive and offers new opportunity in the market. 


\begin{tabular}{|c|c|c|c|}
\hline \multicolumn{4}{|c|}{ Table 1: Survey Results, Intended Merger Outcomes } \\
\hline & & $\begin{array}{c}\text { Of } 9 \\
\text { Respondents }\end{array}$ & $\begin{array}{c}\text { Of } 5 \\
\text { Companies }\end{array}$ \\
\hline \multirow{2}{*}{ Driver for Merger } & Increased Sourcing Abroad & 8 & 4 \\
\hline & Loss of Competitive Advantage & 4 & 3 \\
\hline \multirow{2}{*}{ Intended Benefit } & Maintain Market Share & 6 & 4 \\
\hline & Synergies & 6 & 3 \\
\hline \multirow{2}{*}{ Measurement Tool } & Sales Ratio & 6 & 4 \\
\hline & Cost Savings & 6 & 3 \\
\hline \multirow{2}{*}{\multicolumn{2}{|c|}{$\begin{array}{l}\text { Total Profitability Measures } \\
\text { Total Productivity Measures }\end{array}$}} & 9 & 5 \\
\hline & & 3 & 1 \\
\hline
\end{tabular}

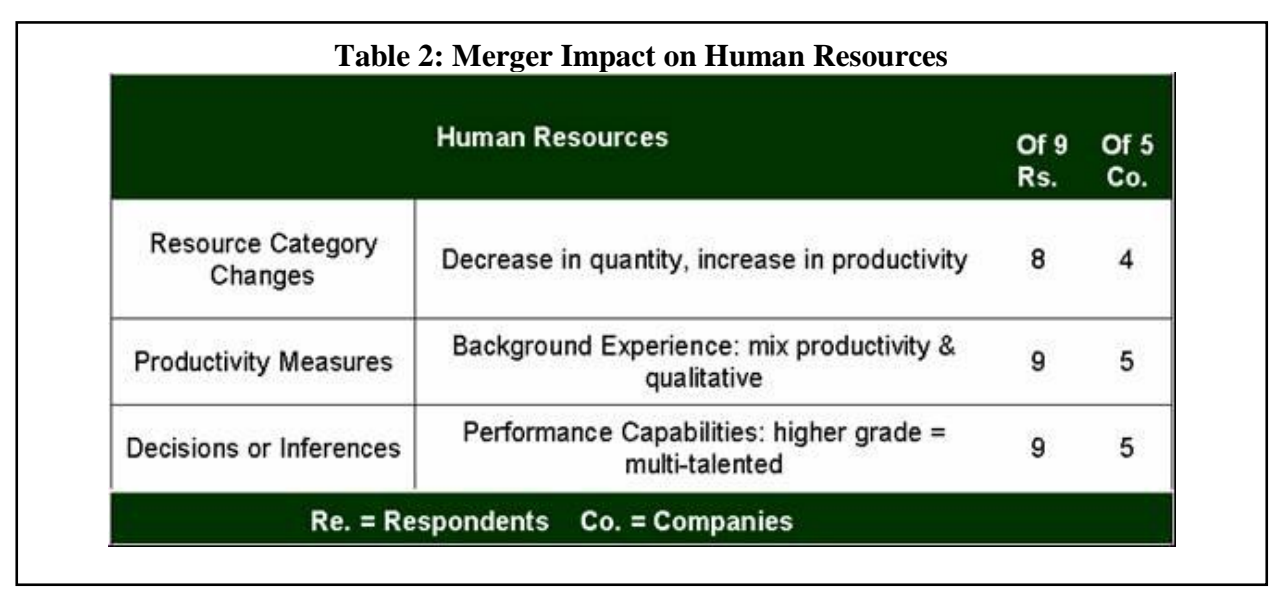

\begin{tabular}{|c|c|c|c|}
\hline \multicolumn{2}{|r|}{ Physical Resources } & Of 9 & Of 5 \\
\hline $\begin{array}{l}\text { Resource Category } \\
\text { Changes }\end{array}$ & $\begin{array}{l}\text { Decrease in facilities (consolidation) led to } \\
\text { increase in productivity }\end{array}$ & 7 & 3 \\
\hline Productivity Measures & Cost and utilization & 9 & 5 \\
\hline Decisions or Inferences & Cost Effectiveness & 7 & 4 \\
\hline \multicolumn{4}{|c|}{ Re. $=$ Respondents Co. $=$ Companies } \\
\hline
\end{tabular}

Tables 4 and 5 show how some desired outcomes are targeting areas of product development, new idea generation, and access to capital markets. Table 4 specifically shows how merged companies try to retain the best 
talents and attempt to improve "knowledge worker productivity" (Drucker, 2000); measuring this outcome is still somewhat subjective, but it is clearly recognized as a key competitive factor. Bundling capital resources to allow new investments in promising projects can also be a forward strategy unless the investment solely focuses on cost savings. Access to capital markets tends to be limited for many traditional textile companies, so that mergers in some cases provide a funding source.

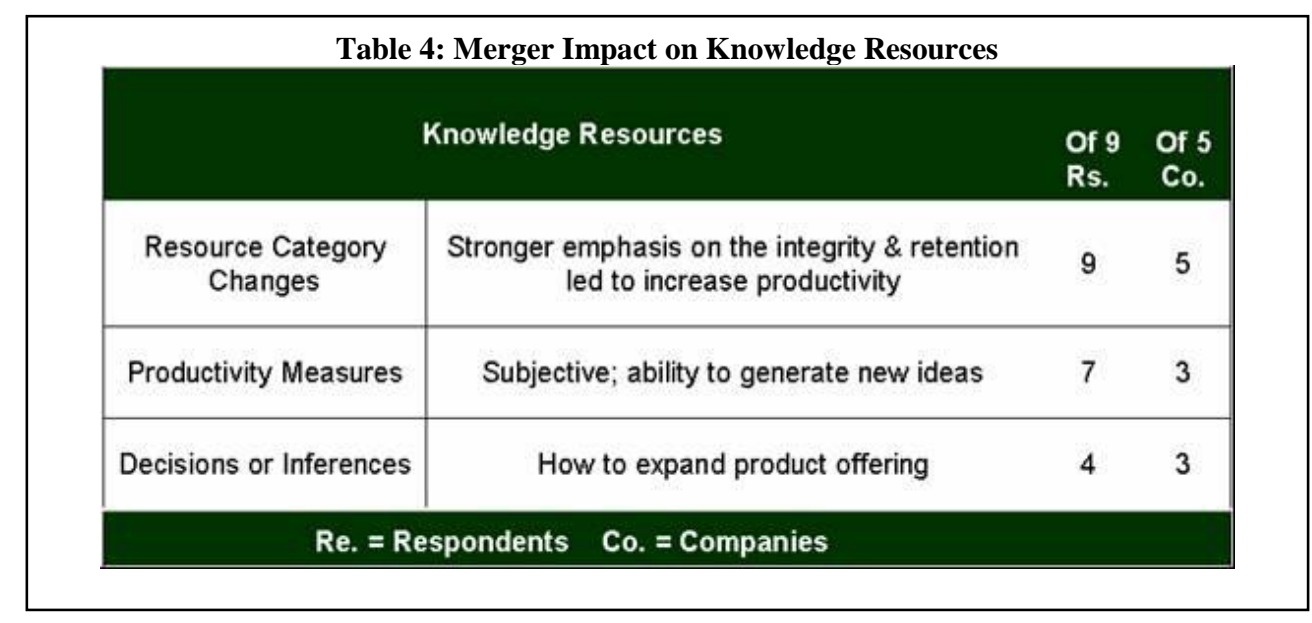

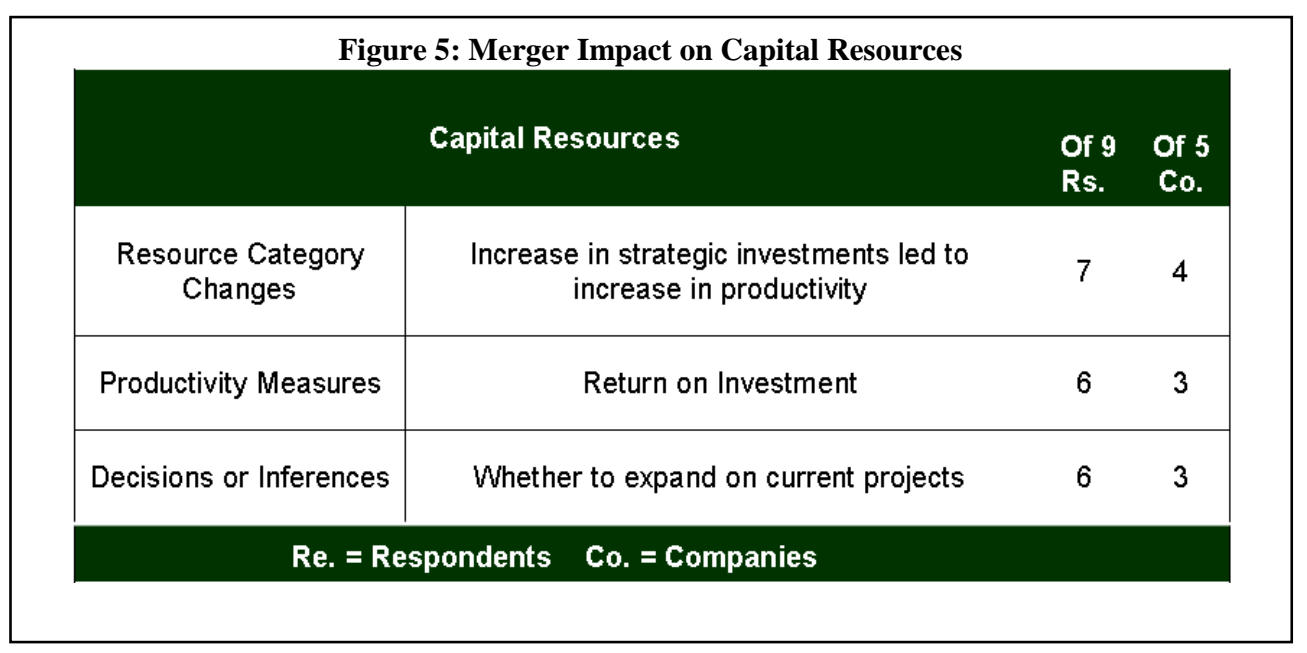

Figure 4 shows how the surveyed companies assessed the merger results. In the interviews it became quite clear that most companies do not necessarily distinguish between productivity and profitability. Figure 4 summarizes the change in productivity to each resource category that was attributed to the merger activity. All respondents completed a scale from -5 to 5 to represent the changes in productivity for each category. The point is not to provide a numerical percentage representing how much productivity will improve (or decrease) for other companies but rather to understand the trend of the impact of mergers on these resources relative to each other. The survey shows that merger activity in this case tends to have the strongest impact on capital and knowledge resources. While the drivers behind the mergers were primarily defensive, the strongest impact was seen in areas that are not solely defensive.

Figure 5 shows the summary of 71 individual strategic activities that were credited with contributing to improved profitability of the merger. The individual activities were grouped into nine main categories shown in Figure 5, with "improved corporate structure" in the leading position, followed by "product differentiation". The 
specific strategic activities for these to categories are shown in Figures 6 and 7, and it becomes clear that improved corporate structure focuses on efficiency and cost while product differentiation focuses on market orientation and technology strategies.
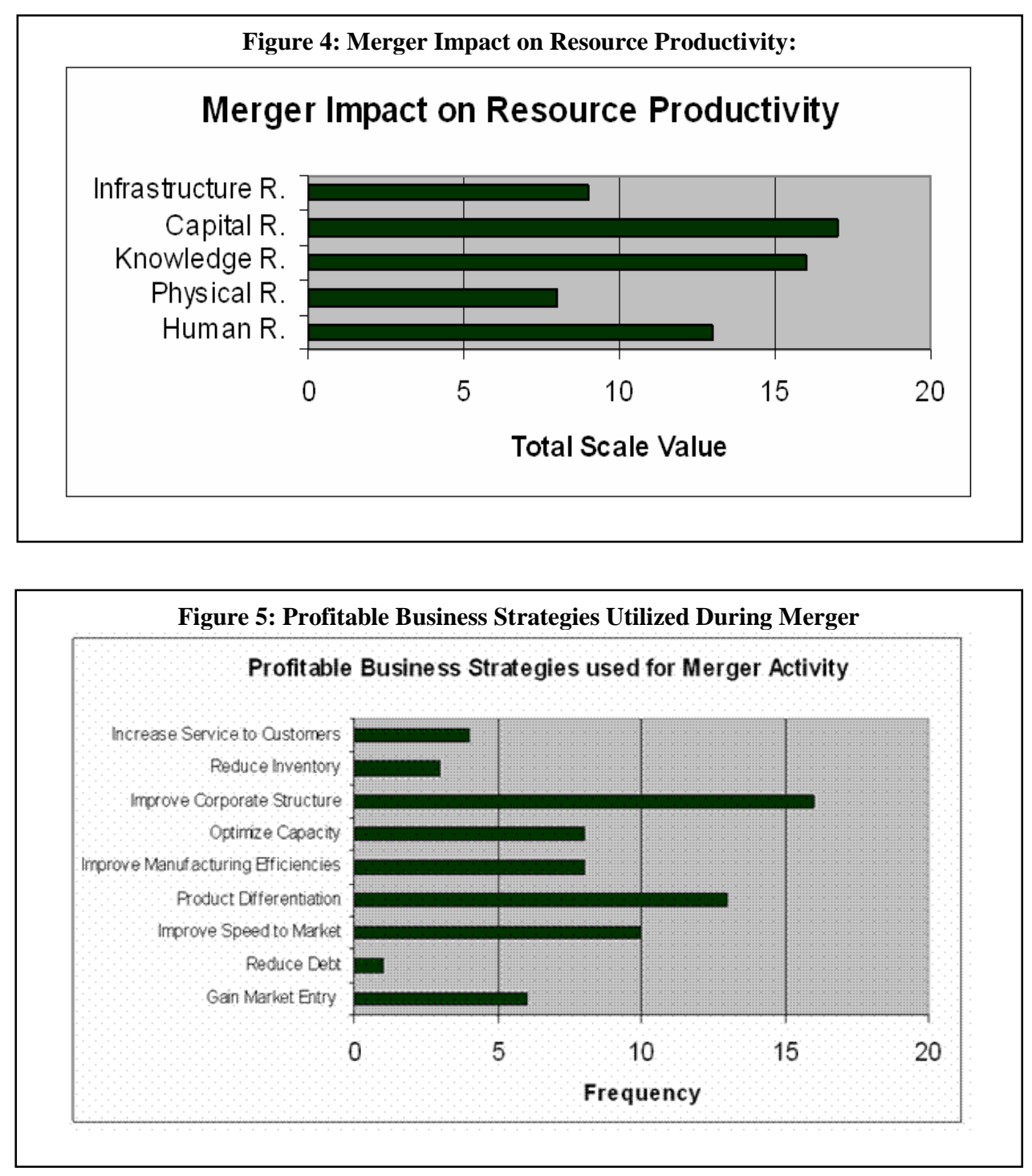

Restructuring primarily involves the traditional downsizing efforts, including the reconfiguration of existing production facilities and the streamlining of corporate functions. Key strategies for product differentiation included the expansion of value added production by emphasizing a product mix that involved lower volume, higher priced products. The ways some of the companies went about executing this business strategy was by aggressively developing key technologies. After the merger activity, they utilized newly acquired technologies to develop higher value and greater functionality. They commercialized proprietary know-how and extended product lines in such ways as: specializing in an area, customizing products, creating new designs, and increasing personnel and advertising resources to improve market access. In addition to product differentiation strategies "improving speed to market" was considered a profitable strategic category to be addressed in mergers. This was achieved by relocating and reconfiguring some assets after the merger, e.g., by relocating product development lines among manufacturing 
facilities. This resulting in a reduction of the cycle time for the introduction of new products and processes by allowing manufacturing personnel to be more involved in the development process. In addition, speed to market was obtained in some cases by shipping directly to customers.
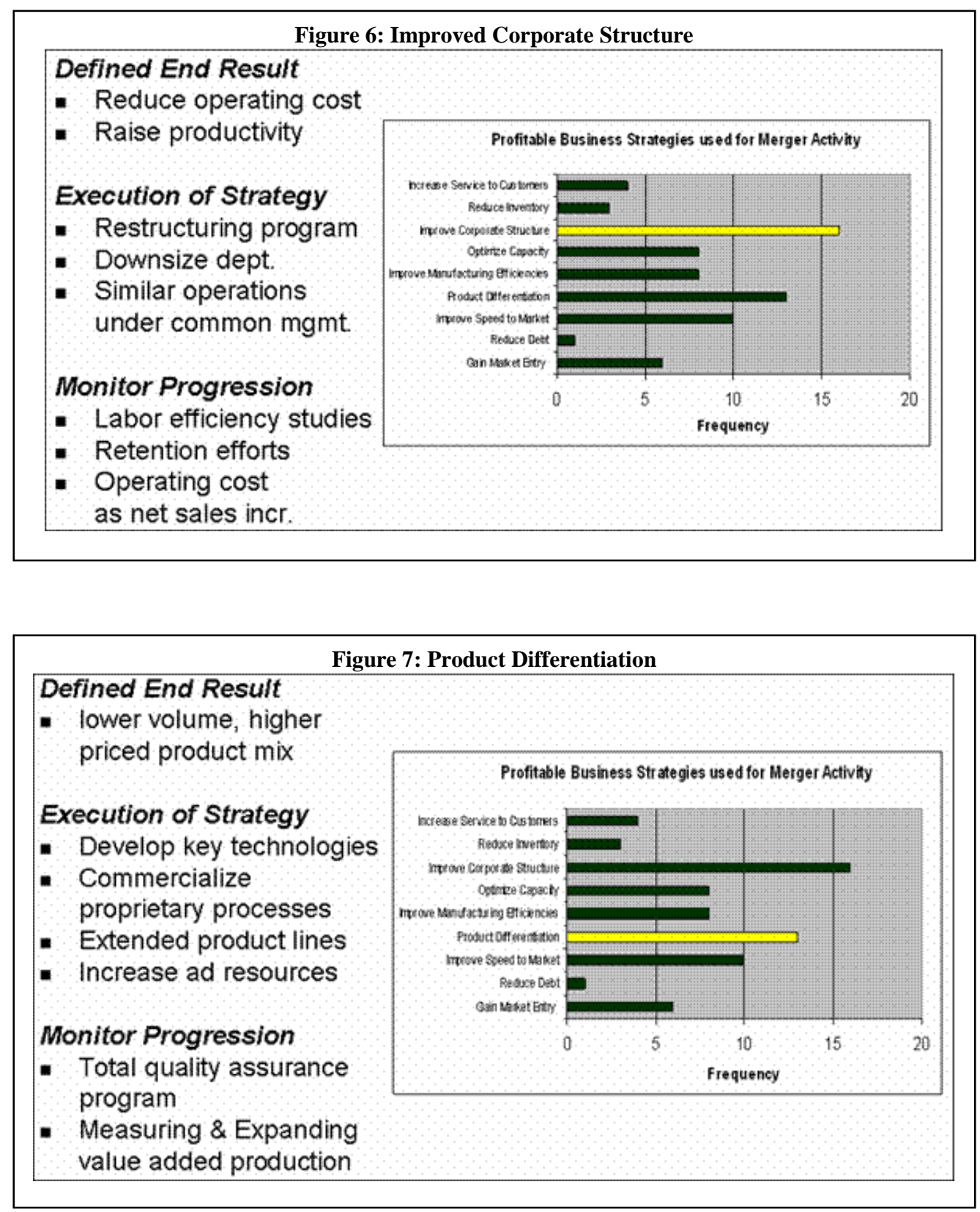

The companies clearly use productivity and profitability measures in combination as an indicator of competitiveness. As such, the companies linked the resource productivities to competitiveness as shown in Figure 8. Knowledge resource productivity is clearly linked to competitiveness ahead of any other resource, and the actual physical resources (e.g., plant equipment) are listed last. This may indicate a shift in relevance of physical resources 
within the industry or it may indicate that this resource category is already at such a level that marginal improvements no longer have significant impact on competitiveness.

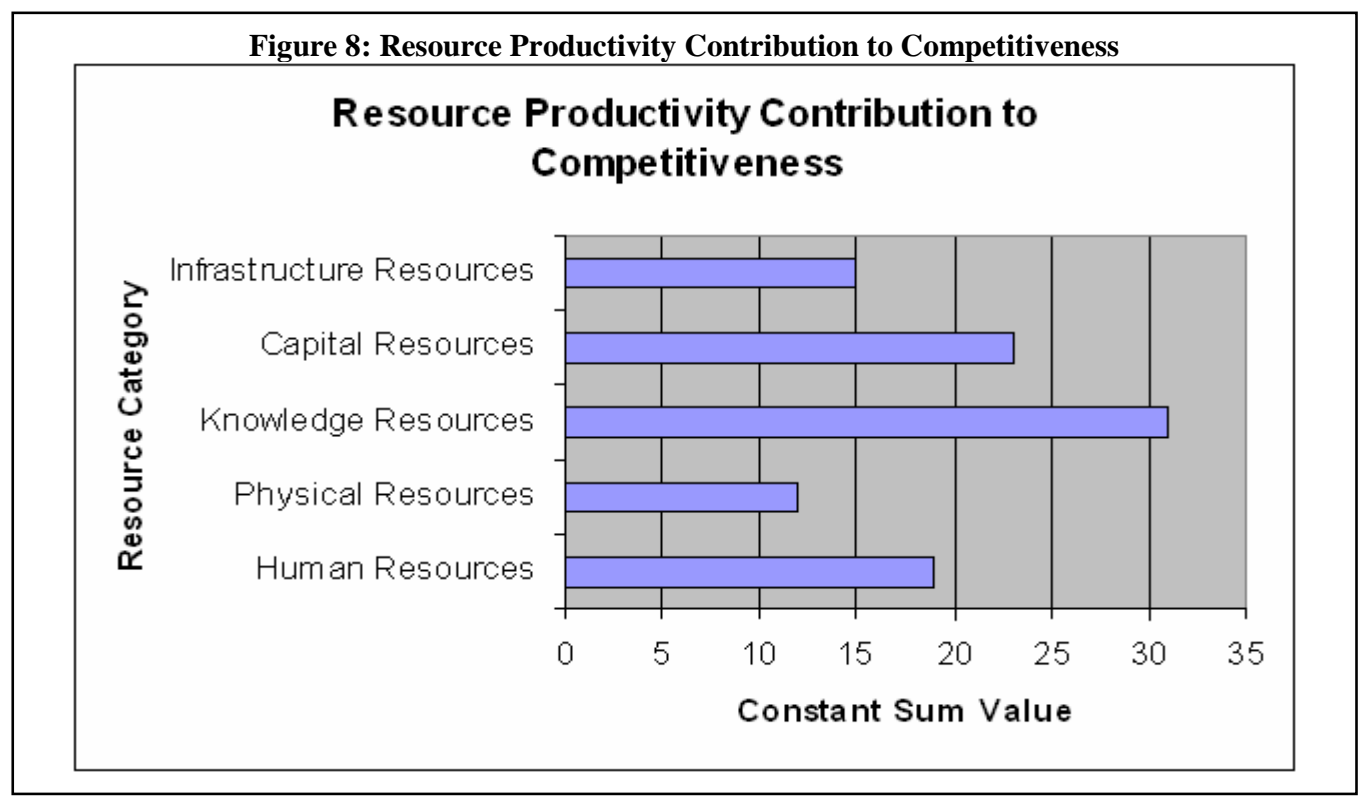

\section{CONCLUSIONS}

- Mergers have significant influence on productivity of Capital and Knowledge Resources.

- Business strategies during merger should focus on improving corporate structure, product differentiation, and/or speed to market.

- $\quad$ Productivity measures need to be coupled with profitability measures to be indicator of competitiveness.

- Productivity of Knowledge Resources is considered the most important contributor to competitiveness.

- Further research into measuring and managing knowledge resources is desirable.

\section{ACKNOWLEDGEMENTS}

The authors would like to express their thanks and gratitude to the Institute of Textile Technology at NC State University that sponsored the research for this paper.

\section{BIBLIOGRAPHY}

1. Baumol, W. J. (1984). U. S. competitiveness and the productivity gap. The Journal of Economic Education, 15(3), 217-224.

2. $\quad$ Drucker, P. F. (1974). Management: Tasks, Responsibilities, Practices. New York: Harper \& Row.

3. Drucker, P. F. (1993). Post-Capitalist Society. New York: Harper Collins Publishers Inc.

4. Drucker, P. F. (2000). The new productivity challenge. Harvard Business Review on strategies for growth (pp. 69-79). Boston, Mass.: Harvard Business School Press.

5. The Economist, How To Make Mergers Work (various feature articles), January 1999.

6. Felgner, B. (2005). Coping with global competition. Home Textiles Today, 26(4), 2-19.

7. Kaplan, S. N., Mitchell, M. L., \& Wruck, K. H. (2000). A clinical exploration of value creation and destruction in acquisitions: Organizational design, incentives, and internal capital markets. Mergers and Productivity (pp. 179-237). Chicago: The University of Chicago Press. 
8. Kaplan, S. N. (2000). Mergers and Productivity. Chicago: University of Chicago Press.

9. Marshall, M., (2007). Productivity in Textiles: How to Correctly Measure the Impact of Mergers and Outsourcing, Masters Thesis at North Carolina State University, College of Textiles.

10. Milberg, W. (Ed.). (2004). Labor and the globalization of production: Causes and consequences of industrial upgrading. New York, N.Y.: Palgrave Macmillan.

11. Morrisett, B., Brown, B., Hettinger, J. (2001), Consolidation Activity Declines, Textile World, Vol. 151, pg. 56.

12. OTEXA (2007), U.S. Department of Commerce, Office of Textiles and Apparel, http://otexa.ita.doc.gov/msrpoint.htm.

13. Plunkett, J. W. 2007). Plunkett's Apparel, Textiles \& Fashions Industry Market research, business trends \& statistics analysis, \& business development support. [Electronic version]. Apparel, Textiles \& Fashions Industry.

14. Porter, M. E. (1990). The Competitive Advantage of Nations. New York: Free Press.

15. Ramcharran, H. (2001). Estimating productivity and returns to scale in the US textile industry. Empirical Economics, 26, 515.

16. Reichard, R. (1997). Productivity: Textiles' ace in the hole. Textile World, 147(1), 19.

17. Reichard, R. (2000). Growing productivity is a plus. Textile World, 150, 13.

18. Reichard, R. S. (2005). Productivity factor. Textile World, 155, 20-20.

19. Sutton, R. I., (2006). Hard Facts, Dangerous Half-Truths, and Total Nonsense: Profiting from EvidenceBased Management, Stanford Executive Briefings, Kantola Productions DVD.

20. U.S. Department of Commerce, Bureau of Industry and Security (2007), http://www.bis.doc.gov/defenseindustrialbaseprograms/osies/defmarketresearchrpts/texreport_ch1.html.

21. U.S. Department of Labor (2007), Bureau of Labor Statistics, http://www.bls.gov/data/home.htm. 


\section{NOTES}

